\title{
Short-Term Effects of Arthroscopic Microfracturation of Knee Chondral Defects in Osteoarthritis
}

\author{
Przemysław Krakowski ${ }^{1, *}$, Robert Karpiński ${ }^{2}$, , Ryszard Maciejewski ${ }^{3}$, Józef Jonak ${ }^{2}(\mathbb{D}$ and \\ Andrzej Jurkiewicz ${ }^{4}$ \\ 1 Chair and Department of Traumatology and Emergency Medicine, Medical University of Lublin, Staszica 11, \\ 20-081 Lublin, Poland \\ 2 Department of Machine Design and Mechatronics, Faculty of Mechanical Engineering, \\ Lublin University of Technology, Nadbystrzycka 36, 20-618 Lublin, Poland; r.karpinski@pollub.pl (R.K.); \\ j.jonak@pollub.pl (J.J.) \\ 3 Department of Human Anatomy, Medical University of Lublin, 20-090 Lublin, Poland; \\ ryszard.maciejewski@umlub.pl \\ 4 Orthopedic Department, Łęczna Hospital, Krasnystawska 52, 21-010 Łęczna, Poland; jurkiewicz16@wp.pl \\ * Correspondence: przemyslawkrakowski@umlub.pl; Tel.: +48-606-665-183
}

Received: 25 October 2020; Accepted: 21 November 2020; Published: 24 November 2020

\begin{abstract}
Purpose: The purpose of this study was to estimate the effect of platelet-rich plasma (PRP) augmentation in microfractures of chondral lesions in elderly individuals. Methods: 29 patients with knee osteoarthritis were enrolled in the single-blinded randomized study. The study group consisted of 16 patients and 13 were in the control group. All surgeries were performed in the same manner. The PRP injection was made in a dry arthroscopy directly over the microfractures. The evaluation was performed preoperatively on the 6th, 12th, and 24th week following the surgery. WOMAC and Lysholm questionnaires were utilized. Results: Microfracturation showed WOMAC improvement in the PRP group ( $p=0.0012)$ and in the control group $(p=0.0042)$. No statistically significant differences between the two groups $(p=0.698)$ have been found. Clinical improvement was noted in the first six weeks after which the effect lasted. In addition, Lysholm score showed no significant differences at the end of the follow-up between both groups $(p=0.941)$. Conclusions: Arthroscopic microfracture improves motor function and reduces pain in patients over 50 years old. PRP augmentation of the procedure is safe, and can accelerate and prolong the therapeutic effect of treatment. Excellent effects of the procedure are observed in the first six weeks, after which the improvement lasts.
\end{abstract}

Keywords: osteoarthritis; cartilage; platelet-rich plasma; cartilage regeneration; mechanical stimulation; microfracturation

\section{Introduction}

Osteoarthritis $[\mathrm{OA}]$ is a complex process, in which degenerative changes appearing in articular cartilage $[\mathrm{AC}]$, subchondral bone, or synovial membrane can lead to joint failure [1]. Hyaline cartilage is the main component of every synovial joint; however, due to its function and structure, it has a very limited capacity for healing [2]. Once the cartilage is damaged, the joint is predisposed to rapid osteoarthritis changes, which lead to irreversible joint failure [2]. OA is mainly considered as a disease of older people, as over one-third of the population over 65 years old present OA in at least one joint [3]; however, factors such as obesity, sports, genetic factors, work, previous injuries or socio-economic status can influence osteoarthritic changes in the joint $[4,5]$ in younger populations. Therefore, researchers seek methods for effective treatment at every disease stage that could decrease disease progress and the need for total joint replacements in the end-stage disease. A range of 
conservative treatment strategies is implemented in the treatment process, including weight loss, daily activity modulation, pharmacological or surgical treatment. Although each of these methods is carried out in the hope of prolonging native joint survival, they are incapable of curing the cartilage defect itself [2]. Total knee replacement is a gold standard in end-stage disease; however, every total joint replacement procedure has its limits in regard to prostheses survival time [6]. The younger the patient is at the time of total knee replacement, the higher risk of revision surgery is expected since a 10 -year survival rate of total knee replacement reaches $81-92 \%$ [6,7]. One of the surgical procedures widely used for treating cartilage defects is microfracture $[\mathrm{MFx}]$ of the subchondral bone, introduced by R. Steadman [8]. The technique in question is relatively easy and inexpensive, while it uses body healing capacity on the ground of clot formed in the cartilage defect. Over the years, the technique has been improved and now steps like removing a calcified subchondral bone, creating a straight even cartilage edges, and performing MFx as close to each other as possible [9] are considered essential. As a result, a rough surface is created onto which a blood clot can attach [10]. The effectiveness of MFx depends on multiple factors such as the size of the defect, age, comorbidities, or genetic factors. Age and the size of the defect are the biggest issues influencing the final effect of the procedure. During MFx, mesenchymal stem cells [MSC] are released from bone marrow. However, after the age of 35, the number of available MSC decreases significantly [11], which is among the key reasons for recommending MFx in individuals below 40 years of age [12]. Moreover, fibrocartilage which fills the defect after MFx is shown to have inferior mechanical properties in comparison with hyaline cartilage [13]. Nevertheless, MFx remains one of the most common procedures carried out by orthopedic surgeons in cartilage defects on account of its simplicity, low cost, or fast recovery; however, methods of augmentation of MFx to broaden its indications are actively sought. The effect of the treatment is the creation of fibrous cartilage, which covers the hyaline cartilage defect. The fibrous cartilage is shown to have inferior mechanical properties in comparison with hyaline cartilage [14,15]. Moreover, the best therapeutic effect is reached when defects smaller than $4 \mathrm{~cm}$ are treated with MFx [16]. Based on animal models, it is proposed that MFx outcomes can be enhanced by augmentation of platelet-rich plasma [PRP] [17]. Since the early eighties, platelet mixtures have been used in medicine to improve skin healing [18]. The interest in PRP has grown rapidly since the first publications of its usage in maxillomandibular surgery $[19,20]$. Chemokines such as transforming growth factor $\beta$ [TGF $\beta]$, Insulin-like growth factor-1 [IGF-1], vascular endothelial growth factor [VEGF], platelet-derived growth factor [PDGF], and bone morphogenic protein-2,4,7 [BMP-2, BMP-4, BMP-7] are found in abundance in PRP $[21,22]$. Some of the chemokines in question can stimulate the migration of stem cells and promote chondrogenesis $[23,24]$. Chondrogenic and anabolic properties of TGF- $\beta$ and IGF-1 have been receiving special interest [25-27]. Studies on animal models show that PRP supplementation of MFx enhances the therapeutic effect of microfractures performed alone [17]. Moreover, PRP supplementation increases newly created cartilage endurance [28]. It is also worth noting that septic arthritis after arthroscopic procedures is lower than 1\% [29] in comparison to total joint replacement in which the infection rate exceeds $2 \%$ [30].

Given the above, it is no surprise that in recent years, augmentation of surgical procedures with PRP has received the growing attention of scholars and surgeons. To date, the effects of MFx with augmentation of PRP on animal models, as well as on human subjects, especially in the knee and ankle joint, have been reported. To the best of our knowledge, at the moment of preparing the study, there is a limited number of papers focusing on PRP usage in arthroscopic MFx procedures in vivo on humans. This study was undertaken to evaluate the role of PRP during arthroscopic MFx procedure in enhancing the clinical effect of surgical procedure, especially in an older age group. This study can offer additional information about the possibility of enhancing minimally invasive techniques, such as MFx, with safe and easily accessible factors such as PRP, while most of the former works have focused on a younger population with mean age less than 50 years old [31]. Moreover, the aim of this study was to evaluate how fast clinical improvement occurs, in contrast to most of the published papers that concentrated on long-term effects without adequate evaluation of early clinical changes [31]. 


\section{Materials and Methods}

The cohort consisted of patients from the outpatient clinic of District Hospital in Leczna (Kranystawska 52 St. 21-010 Łęczna, Poland) who had persistent pain in knee joints with early osteoarthritic changes estimated in Kellgren-Lawrence 1-2. Each patient underwent prior conservative therapy without an acceptable effect on pain and function. The study group included individuals aged 50 to 70 years. Of the group, 29 patients were included in the study group out of whom 13 were in the control group and 16 in the study group. Females represented the majority in the study and the control groups, i.e., $69 \%$ and $61 \%$, respectively. In order to narrow the study, group-specific exclusion criteria that could create biomechanical or biochemical bias were specified:

- Previous fractures of the knee joint

- Varus or valgus deformity of the knee joint exceeding 15 degrees

- Lack of full range of motion of the knee joint

- Clinically diagnosed instability of knee ligaments

- Earlier qualification for unilateral or total knee replacement

- Diabetes

- Hematologic disorders

- Rheumatic diseases

- Active oncological process.

A detailed medical history was taken, and a physical examination was performed in every case.

The study was blinded for the patients, who did not know whether plain MFx or MFx with augmentation with PRP was performed. At the selection for the study, each participant was given a number and randomization was conducted with the use of "=rand" function in Microsoft Excel, which enabled random selection for the control and study group.

\subsection{Study and Control Group Description}

A total of 29 patients were included in the study, 19 women and 10 men. No adverse effects of the procedure were recorded in early and late follow-up. The PRP and the control group were comparable with respect to age (63 vs. 59) and BMI (30.5 vs. 31). Of the 29 participants, only four declared history of trauma at the onset of symptoms, 3 of whom were in the PRP group. There was a substantial difference in the involvement of opposite extremity between both groups. In the PRP group, 37\% of participants had pain in an opposite extremity. On the contrary, over 75\% of patients in the control group reported complaints about the function of an opposite lower extremity. All individuals enrolled in the study were provided with some form of conservative treatment prior to the surgery, including physiotherapy, viscosupplementation, or steroid injection. The most common form of conservative treatment was physiotherapy, attended by $75 \%$ of patients from the PRP group and $84.6 \%$ of patients from the control group. In 25 individuals, grade IV cartilage lesions were diagnosed. The remaining four presented grade III cartilage lesions. The entire study and the control group presented grade III or IV cartilage lesions in the knee. The most common site of cartilage defect in the PRP group was medial femoral condyle, whereas in the control group, it was medial tibial condyle. The medial compartment of the knee and patella-femoral joint presented the majority of chondral lesions locations. Cartilage lesions on lateral femoral condyle were found in 4 cases and 2 in lateral tibial condyle. Concomitant knee lesions included meniscal tears $(n=20)$, which were excised during the surgery. The medial meniscus was mostly involved in the degenerative process. $62.5 \%$ of individuals in the PRP group had medial meniscus lesions. A comparable number of participants presented lesions of the medial meniscus in the control group $(61.5 \%)$. The results are shown in Table 1. 
Table 1. Clinical and baseline characteristics.

\begin{tabular}{|c|c|c|c|}
\hline Parameter & PRP Group N = 16 & Control Group N = 13 & $p$-Value \\
\hline Age, year (mean $\pm \mathrm{SD})$ & $63 \pm 3.8$ & $59 \pm 6.8$ & n. $\mathrm{s}(p=0.069)$ \\
\hline Female gender, $\mathrm{n}(\%)$ & $11(68.7 \%)$ & $8(61.5 \%)$ & n. $\mathrm{s}(p=0.685)$ \\
\hline $\mathrm{BMI}($ mean $\pm \mathrm{SD})$ & $30.6 \pm 2.85$ & $31 \pm 4.1$ & n. s $(p=0.763)$ \\
\hline Duration of symptoms, months & $53.2 \pm 66.9$ & $78 \pm 81.7$ & n. $\mathrm{s}(p=0.539)$ \\
\hline History of trauma, n (\%) & $3(18.75 \%)$ & $1(7.7 \%)$ & n. $\mathrm{s}(p=0.391)$ \\
\hline Involvement of the dominant extremity, $\mathrm{n}(\%)$ & $5(31.25 \%)$ & $6(46.15 \%)$ & n. $\mathrm{s}(p=0.411)$ \\
\hline Opposite extremity involvement, n (\%) & $6(37.5 \%)$ & $10(77 \%)$ & $p=0.034$ \\
\hline Prior to surgery physiotherapy, n (\%) & $12(75 \%)$ & $11(84.6 \%)$ & n. $\mathrm{s}(p=0.525)$ \\
\hline Medial meniscus lesions, $\mathrm{n}(\%)$ & $10(62.5 \%)$ & $8(61.5 \%)$ & n. $\mathrm{s}(p=0.958)$ \\
\hline Lateral meniscus lesions, $\mathrm{n}(\%)$ & $5(31.25 \%)$ & $3(23 \%)$ & n. $\mathrm{s}(p=0.624)$ \\
\hline Bilateral meniscus lesions, n (\%) & $3(18.75 \%)$ & $3(23 \%)$ & n. $\mathrm{s}(p=0.775)$ \\
\hline MFC cartilage lesions grade III-IV, $n(\%)$ & $11(68.75 \%)$ & $6(46.15 \%)$ & n. $s(p=0.219)$ \\
\hline LFC cartilage lesions grade III-IV, $\mathrm{n}(\%)$ & $3(18.75 \%)$ & $1(7.6 \%)$ & n. $\mathrm{s}(p=0.391)$ \\
\hline MTC cartilage lesions grade III-IV, n (\%) & $7(43.75 \%)$ & $9(69.2 \%)$ & n. $\mathrm{s}(p=0.170)$ \\
\hline LTC cartilage lesions grade III-IV, n (\%) & $2(12.5 \%)$ & $0(0 \%)$ & n. $\mathrm{s}(p=0.187)$ \\
\hline PFJ cartilage lesions grade III-IV, $\mathrm{n}(\%)$ & $8(50 \%)$ & $2(15 \%)$ & n. $\mathrm{s}(p=0.051)$ \\
\hline
\end{tabular}

\subsection{Surgical Procedure}

Prior to the surgery, $60 \mathrm{~mL}$ of peripheral blood was collected for PRP preparation using the Arthrex Angel System ${ }^{\mathrm{TM}}$. The arthroscopy was conducted in a standard procedure with the use of anteromedial and anterolateral incisions and 30-degree optic. Arthroscopic debridement of loose bodies and the torn meniscus was performed; chondral defects were visualized and graded according to Outerbridge classification [32]. After identification of chondral defect, the surface of the defect was cleansed from the calcified subchondral bone (Figure 1), the edges of the defect were cut to create even edges, and microfractures were done with the use of angulated awls. The depth of the microfractures was estimated by observing the blood or fat outflow from the microfracture. After the microfractures were created, the joint was drained from all the residing liquid. PRP was injected directly over the cartilage defect using the dry arthroscopy technique (Figure 2). The PRP injected into the lesion was in direct contact with exposed collagen fibers; therefore, endogenous activation of PRP and fibrin network production started at the lesion site [33]. No suction drains were used after the surgical procedures.

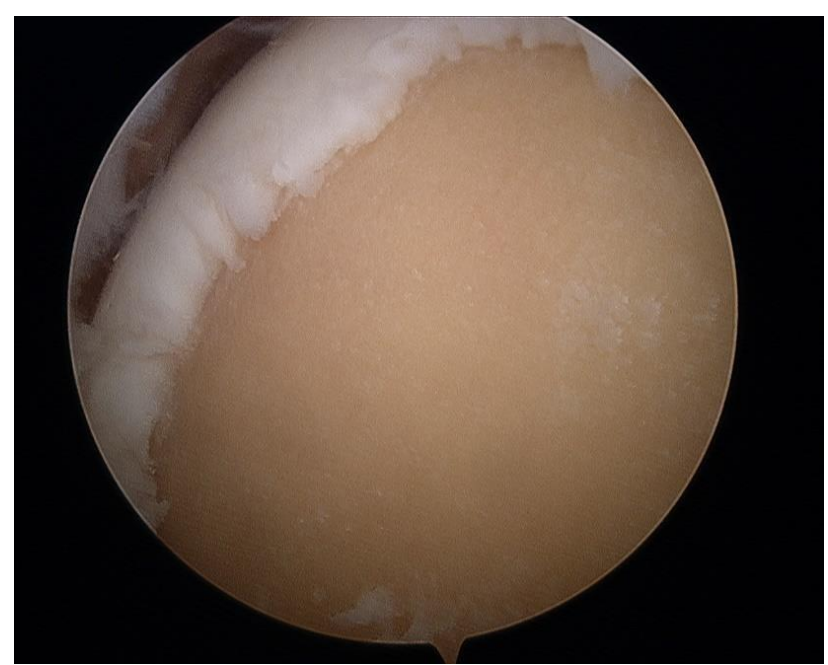

Figure 1. Preparation of microfracturation zone. 


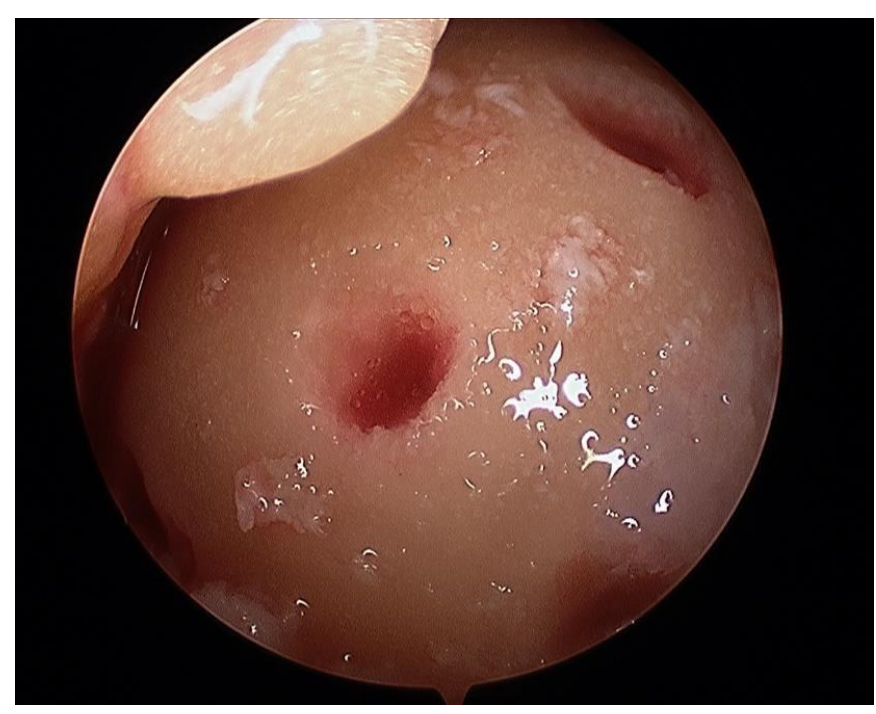

Figure 2. Microfractures in dry arthroscopy view prior to PRP injection.

\subsection{Post-Operative Care}

Each patient was mobilized on the first day after the surgery and full range of motion without weight-bearing was encouraged. The patients were discharged from the hospital on the second day after the surgery and assisted walking with crutches without full weight-bearing was encouraged for 6 weeks after the surgery. Isometric exercises were introduced from day 1 and carried out for 6 weeks. After 6 weeks, the participants were allowed to walk with full weight-bearing without the assistance of crutches. Follow-up was performed in an out-patient clinic after 2, 6, 12, and 24 weeks.

\subsection{Data Acquisition}

For reliable and standardized data collection, The Western Ontario and McMaster Universities Osteoarthritis Index [WOMAC] 3.0 [34] in VAS [Visual Analogue Scale] version and Lysholm Knee Scoring Scale [35] were utilized. WOMAC questionnaires were filled prior to the surgery, as well as 6, 12, and 24 weeks after the surgery. Lysholm questionnaire was filled out prior to the surgery and after 24 weeks. Each participant has given written consent upon admission to the hospital that utilized medical data for treatment and clinical applications. The hospital holds all the necessary approvals and accreditations related to patient data processing in the treatment and research fields. Prior to admission to the Orthopedics and Traumatology Department, each participant signed their consent to the processing of personal and medical data. The study was approved by the Bioethical Committee by Medical University in Lublin with the number of approval 200/2013/KB/V and performed in accordance with Good Clinical Practice regulations.

\subsection{Statistical Analysis}

The statistical analysis was carried out using the Statistica 13.1 software. To obtain statistically significant differences, the level of significance was set a priori at $\alpha=0.05$. Intra- and inter-group comparisons for a series of results with distributions close to normal were carried out using ANOVA with repeatable measurements in qualitative analysis of changes and single-factor ANOVA in quantitative analysis. The following prerequisites for the use of ANOVA/ RM ANOVA are fulfilled [36]:

- measurability of the dependent variable on a scale of at least a range;

- normality of the variable distribution within each group;

- independence of measurements;

- uniformity of variance in all groups;

- homogeneity of covariance of measurements in the same object; 
- $\quad$ sphericity (no correlation between consecutive measurements).

To check for normality, Kolmogorov-Smirnov tests were employed. The sphericity was tested with the Mauchly test. In the case of Lysholm results, the assumption of sphericity was fulfilled and one-dimensional tests were used in the analysis. In the case of the analyzed WOMAC data, the Mauchly test turned out to be significant $(p<0.05)$, i.e., the assumption of sphericity was violated. In this case, ANOVA with repeated measurements could generate incorrect results. Thus, further analyses have used the multidimensional analysis of variance, launching the Wilks', Pillai's, Hotelling's, and Roy's multidimensional tests and the Greenhouse-Geisser and Huynh-Feldt tests, which do not require the sphericity assumption to be fulfilled. In order to determine whether there were statistically significant differences between the groups and within the individual groups, the significance of the difference in variance relating to the variability between the groups and the variance within the groups was tested, the analysis was carried out using a single-factor ANOVA. Categorical variables were compared using the Chi-square test. When comparing the groups with regard to clinical outcomes, the null hypothesis was the absence of a difference in the mean scores.

\section{Results}

All participants enrolled in the study presented with poor joint function measured in Lysholm score. WOMAC questionnaires showed overall great pain, stiffness and poor functionality in daily activities. Regardless of randomization preoperative WOMAC scores in the PRP group were higher than in the control group. Average WOMAC score in the PRP group was 1352 and in the control group-1122. Also, Lysholm scores were slightly lower in the study group 49 compared with 53 in the control group. In both groups, a significant decrease in WOMAC score and increase in Lysholm scores were observed. Significant improvement in WOMAC score was shown both in the PRP group $(p=0.012)$ and in the control group $(p=\mathbf{0 . 0 4 2})$. After that time the changes in both groups in WOMAC score were insignificant $(p>0.05)$. At the end of the follow-up, the mean Lysholm score ranged 77 in the PRP group and 76 in the control group. WOMAC scores also decreased significantly postoperatively in both control and the PRP group respectively 573 and 681. At the end of the follow-up, the clinical improvement was shown in both PRP and the control group. WOMAC score decreased significantly in the PRP group $(p=0.029)$. The control group showed a decrease in overall WOMAC score at the end of the follow-up, however, it was not statistically significant $(p=0.099)$. The improvement in Lysholm score was statistically significant in the PRP group $(p=0.000)$ and the control group $(p=0.001)$. The results are shown in Tables $2-4$ and Figures $3-7$.

Table 2. Results of RM ANOVA statistical analysis.

\begin{tabular}{cccc}
\hline Scale & Test & Control Group & PRP \\
\hline \multirow{2}{*}{ WOMAC Total } & Wilks', Pillai's, Hotelln's, Roy's & 0.014 & 0.004 \\
& G-G, H-F & 0.000 & 0.000 \\
WOMAC Stiffness & Wilks', Pillai's, Hotelln's, Roy's & 0.028 & 0.002 \\
& G-G, H-F & 0.012 & 0.000 \\
WOMAC Function & Wilks', Pillai's, Hotelln's, Roy's & 0.016 & 0.004 \\
& G-G, H-F & 0.000 & 0.000 \\
WOMAC Pain & Wilks', Pillai's, Hotelln's, Roy's & 0.012 & 0.007 \\
Lysholm & G-G, H-F & 0.000 & 0.000 \\
& Univariate tests & 0.001 & 0.000 \\
\hline
\end{tabular}


Table 3. Results from statistical analysis of WOMAC and Lysholm score for the PRP and control group.

\begin{tabular}{|c|c|c|c|c|}
\hline \multicolumn{5}{|c|}{ WOMAC Score PRP Group TOTAL } \\
\hline & Preoperative & Postoperative 6 weeks & Postoperative 12 weeks & Postoperative 24 weeks \\
\hline Preoperative & - & 0.012 & 0.015 & 0.029 \\
\hline Postoperative 6 weeks & 0.012 & - & 1.000 & 0.987 \\
\hline Postoperative 12 weeks & 0.015 & 1.000 & - & 0.995 \\
\hline Postoperative 24 weeks & 0.029 & 0.987 & 0.995 & - \\
\hline \multicolumn{5}{|c|}{ WOMAC Control Group TOTAL } \\
\hline Preoperative & - & 0.042 & 0.034 & 0.099 \\
\hline Postoperative 6 weeks & 0.042 & - & 1.000 & 0.983 \\
\hline Postoperative 12 weeks & 0.034 & 1.000 & - & 0.968 \\
\hline Postoperative 24 weeks & 0.099 & 0.983 & 0.968 & - \\
\hline \multicolumn{5}{|c|}{ WOMAC score PRP Group STIFFNESS } \\
\hline Preoperative & - & 0.009 & 0.027 & 0.036 \\
\hline Postoperative 6 weeks & 0.009 & - & 0.977 & 0.953 \\
\hline Postoperative 12 weeks & 0.027 & 0.977 & - & 1.000 \\
\hline Postoperative 24 weeks & 0.036 & 0.953 & 1.000 & - \\
\hline \multicolumn{5}{|c|}{ WOMAC Control Group STIFFNESS } \\
\hline Preoperative & - & 0.347 & 0.407 & 0.559 \\
\hline Postoperative 6 weeks & 0.347 & - & 1.000 & 0.984 \\
\hline Postoperative 12 weeks & 0.407 & 1.000 & - & 0.994 \\
\hline Postoperative 24 weeks & 0.559 & 0.984 & 0.994 & - \\
\hline \multicolumn{5}{|c|}{ WOMAC score PRP Group Function } \\
\hline Preoperative & - & 0.015 & 0.017 & 0.034 \\
\hline Postoperative 6 weeks & 0.015 & - & 1.000 & 0.990 \\
\hline Postoperative 12 weeks & 0.017 & 1.000 & - & 0.994 \\
\hline Postoperative 24 weeks & 0.034 & 0.990 & 0.994 & - \\
\hline \multicolumn{5}{|c|}{ WOMAC Control Group Function } \\
\hline Preoperative & - & 0.052 & 0.045 & 0.121 \\
\hline Postoperative 6 weeks & 0.052 & - & 1.000 & 0.981 \\
\hline Postoperative 12 weeks & 0.045 & 1.000 & - & 0.972 \\
\hline Postoperative 24 weeks & 0.121 & 0.981 & 0.972 & - \\
\hline \multicolumn{5}{|c|}{ WOMAC score PRP Group Pain } \\
\hline Preoperative & - & 0.012 & 0.018 & 0.029 \\
\hline Postoperative 6 weeks & 0.012 & - & 0.999 & 0.988 \\
\hline Postoperative 12 weeks & 0.018 & 0.999 & - & 0.998 \\
\hline Postoperative 24 weeks & 0.029 & 0.988 & 0.998 & - \\
\hline \multicolumn{5}{|c|}{ WOMAC Control Group Pain } \\
\hline Preoperative & - & 0.015 & 0.008 & 0.033 \\
\hline Postoperative 6 weeks & 0.015 & - & 0.995 & 0.989 \\
\hline Postoperative 12 weeks & 0.008 & 0.995 & - & 0.947 \\
\hline Postoperative 24 weeks & 0.033 & 0.989 & 0.947 & - \\
\hline \multicolumn{5}{|c|}{ Lysholm score PRP Group } \\
\hline Preoperative & - & - & - & 0.000 \\
\hline Postoperative 24 weeks & 0.000 & - & - & - \\
\hline \multicolumn{5}{|c|}{ Lysholm score Control Group } \\
\hline Preoperative & - & - & - & 0.001 \\
\hline Postoperative 24 weeks & 0.001 & - & - & - \\
\hline
\end{tabular}


Table 4. Comparison of results in PRP and the control group.

\begin{tabular}{|c|c|c|c|}
\hline Parameter & PRP Group & Control Group & $p$-Value \\
\hline \multicolumn{4}{|c|}{ WOMAC Total mean $( \pm \mathrm{SD})$} \\
\hline Preoperative & $1354.2( \pm 627.3)$ & $1122.6( \pm 542.9)$ & n. $\mathrm{s}(p=0.327)$ \\
\hline Postoperative 6 weeks & $602.6( \pm 604.9)$ & $487.8( \pm 574.6)$ & n. $s(p=0.625)$ \\
\hline Postoperative 12 weeks & $626.4( \pm 686.5)$ & $467.7( \pm 581.1)$ & n. $\mathrm{s}(p=0.534)$ \\
\hline Postoperative 24 weeks & $681.8( \pm 731.3)$ & $573.5( \pm 665.3)$ & n. $s(p=0.698)$ \\
\hline \multicolumn{4}{|c|}{ WOMAC Pain mean $( \pm S D)$} \\
\hline Preoperative & $268.6( \pm 133.5)$ & $307.1( \pm 129.7)$ & n. $\mathrm{s}(p=0.463)$ \\
\hline Postoperative 6 weeks & $116.2( \pm 120.1)$ & $127.5( \pm 145.1)$ & n. $s(p=0.828)$ \\
\hline Postoperative 12 weeks & $122.5( \pm 139.7)$ & $114.1( \pm 137.7)$ & n. $\mathrm{s}(p=0.878)$ \\
\hline Postoperative 24 weeks & $131.6( \pm 147.2)$ & $145.3( \pm 167.1)$ & n. $s(p=0.825)$ \\
\hline \multicolumn{4}{|c|}{ WOMAC Stiffness mean $( \pm S D)$} \\
\hline Preoperative & $110.2( \pm 61.2)$ & $71.5( \pm 38.4)$ & n. $s(p=0.070)$ \\
\hline Postoperative 6 weeks & $41.8( \pm 49.3)$ & $39.5( \pm 47.7)$ & n. $\mathrm{s}(p=0.903)$ \\
\hline Postoperative 12 weeks & $50.3( \pm 59.2)$ & $41.5( \pm 51.6)$ & n. $s(p=0.692)$ \\
\hline Postoperative 24 weeks & $52.7( \pm 64.0)$ & $46.4( \pm 55.8)$ & n. $\mathrm{s}(p=0.793)$ \\
\hline \multicolumn{4}{|c|}{ WOMAC Function mean $( \pm S D)$} \\
\hline Preoperative & $975.4( \pm 449.2)$ & $744.0( \pm 397.2)$ & n. $s(p=0.178)$ \\
\hline Postoperative 6 weeks & $444.6( \pm 449.2)$ & $320.8( \pm 387.9)$ & n. $s(p=0.462)$ \\
\hline Postoperative 12 weeks & $453.6( \pm 495.9)$ & $312.1( \pm 397.4)$ & n. $\mathrm{s}(p=0.435)$ \\
\hline Postoperative 24 weeks & $497.4( \pm 530.4)$ & $381.8( \pm 444.9)$ & n. $s(p=0.556)$ \\
\hline \multicolumn{4}{|c|}{ Lysholm. mean $( \pm S D)$} \\
\hline Preoperative & $49.25( \pm 12.86)$ & $53.08( \pm 11.06)$ & n. $s(p=0.427)$ \\
\hline Postoperative 24 weeks & $77.06( \pm 17.01)$ & $76.54( \pm 18.93)$ & n. $s(p=0.941)$ \\
\hline
\end{tabular}

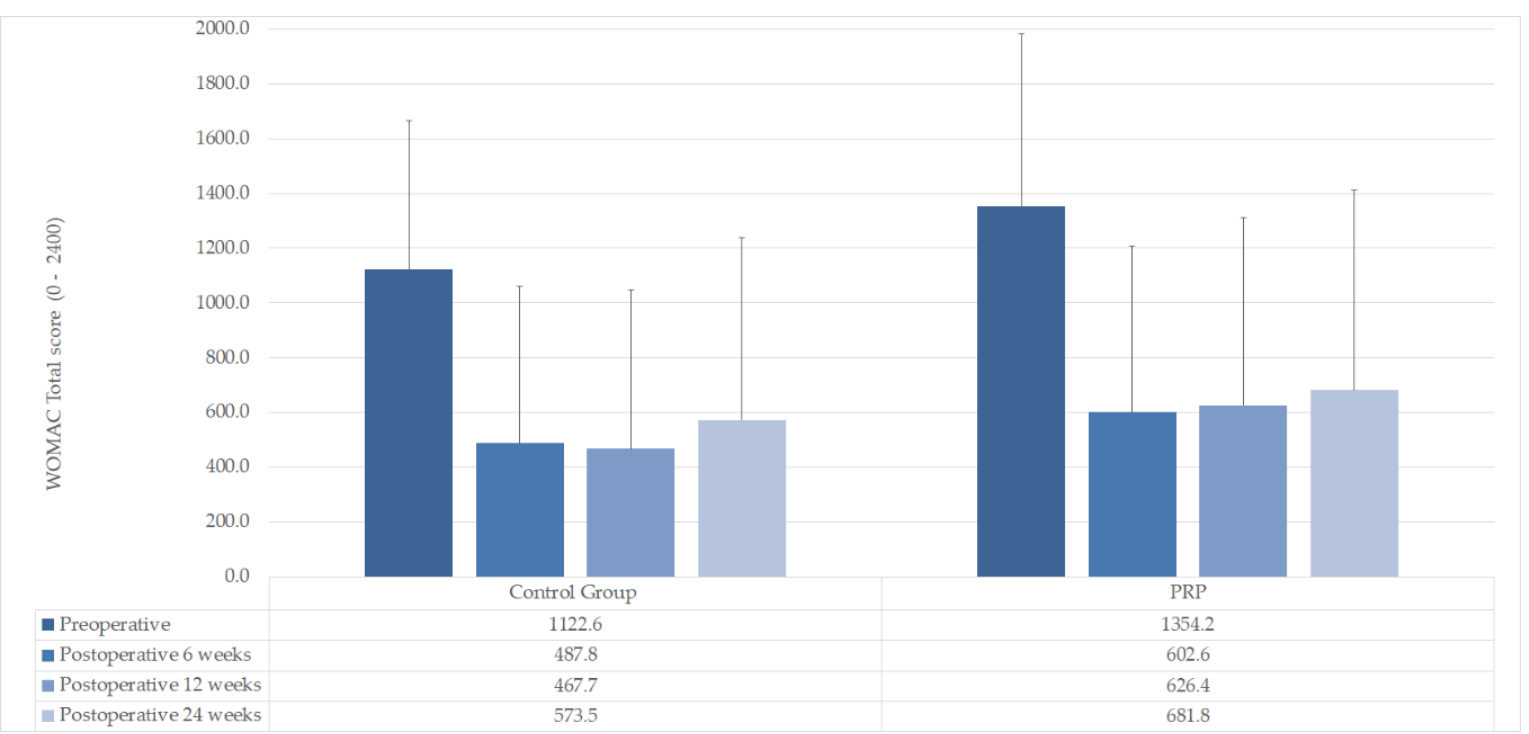

Figure 3. Preoperative vs postoperative total WOMAC score. 


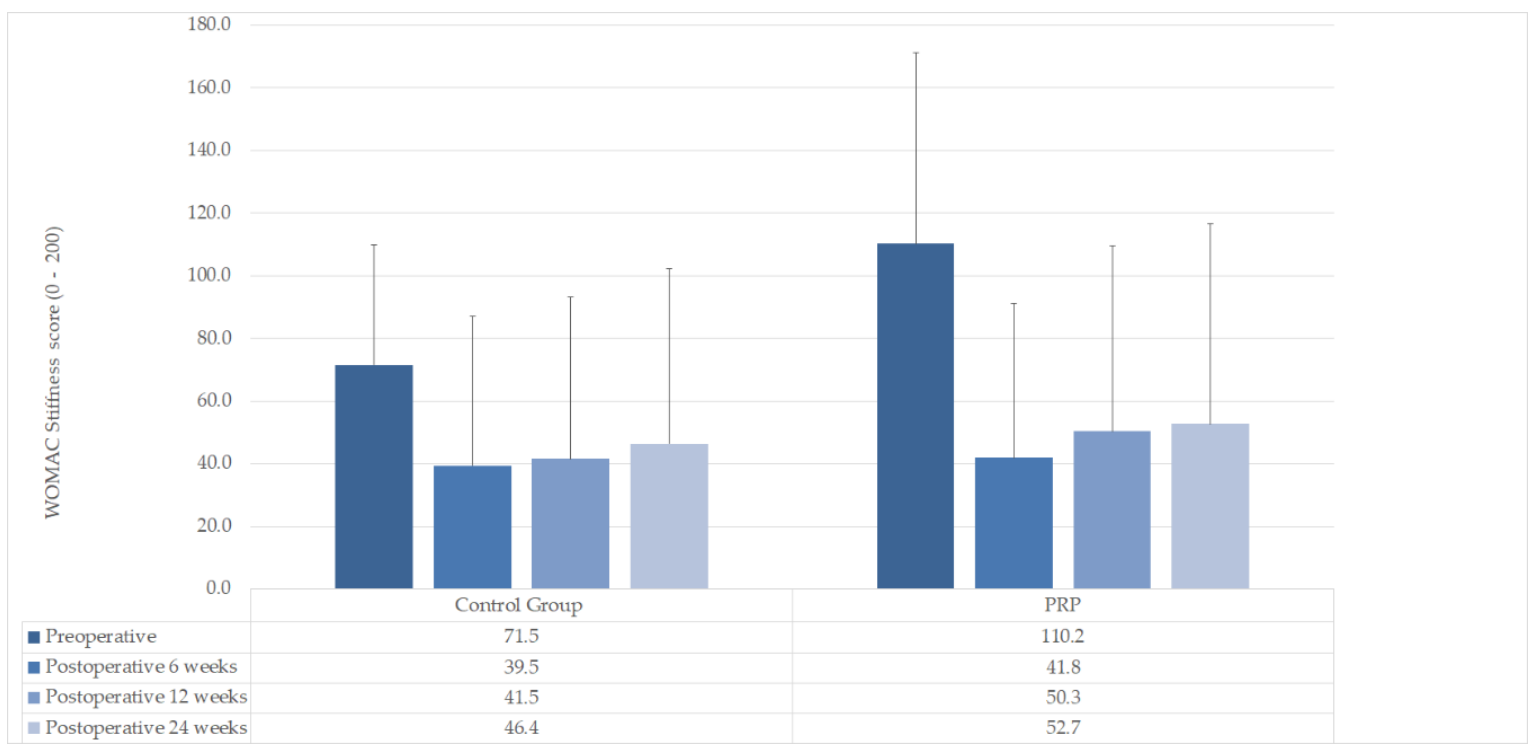

Figure 4. Preoperative vs postoperative stiffness WOMAC scores.

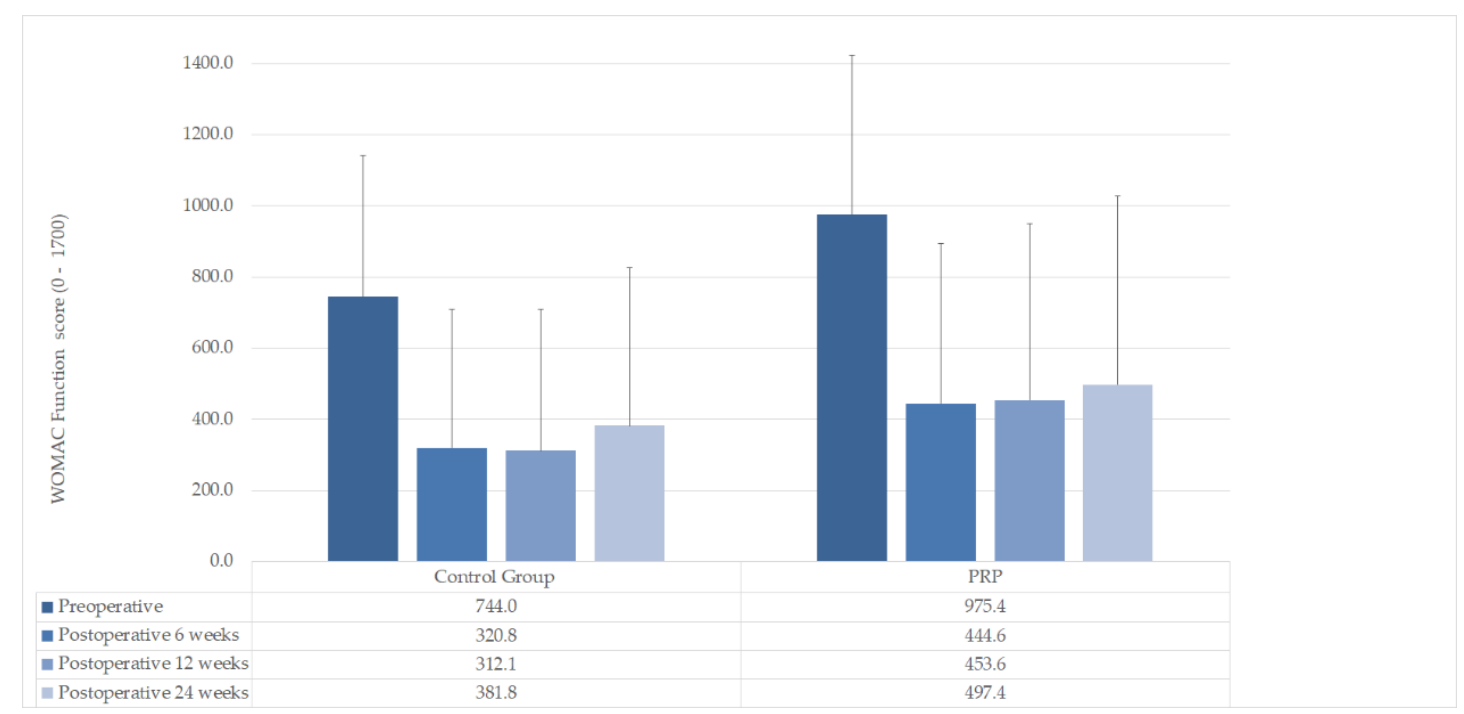

Figure 5. Preoperative vs postoperative function WOMAC scores.

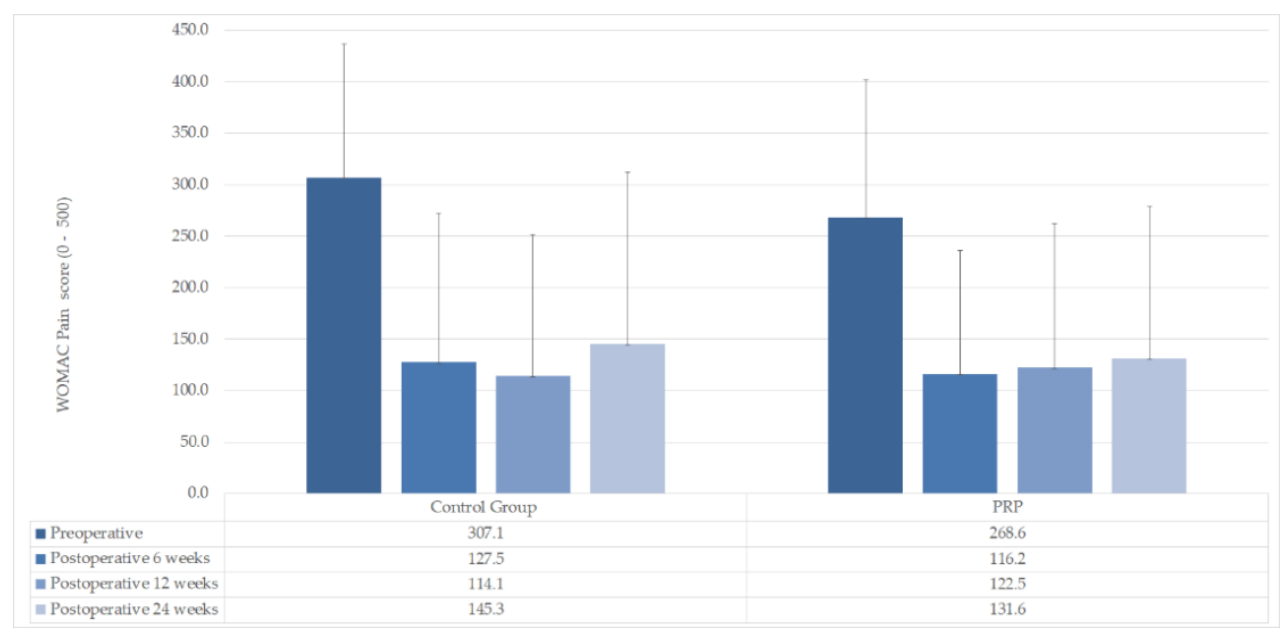

Figure 6. Preoperative vs postoperative pain WOMAC scores. 


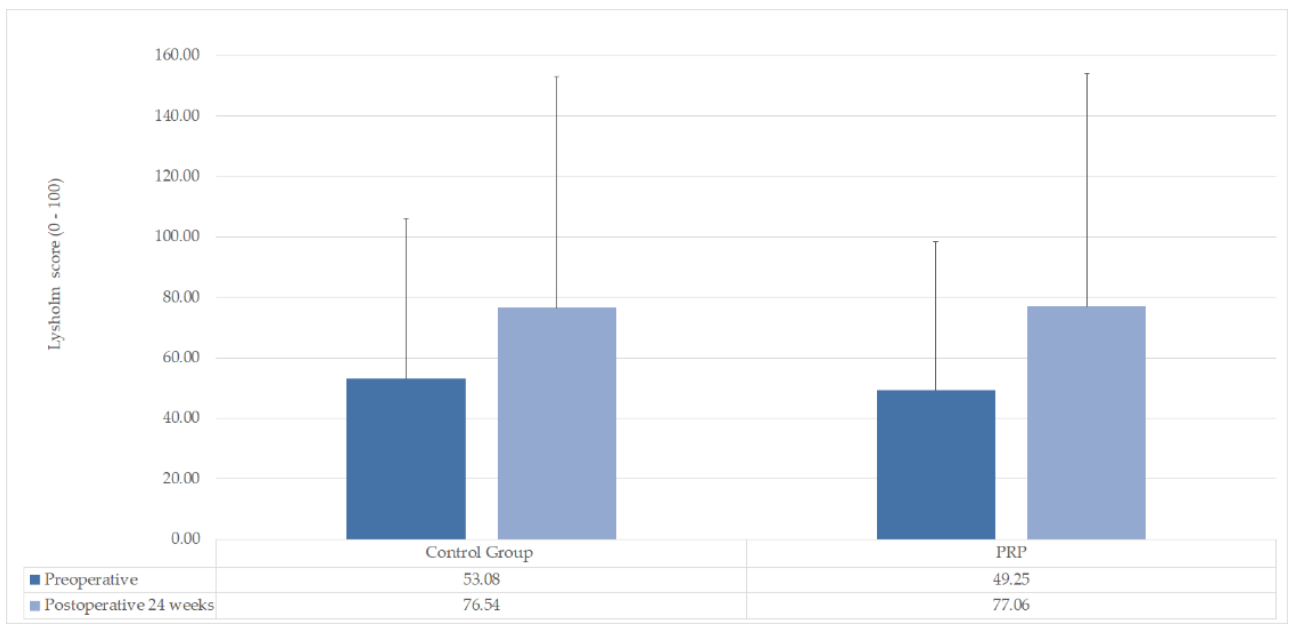

Figure 7. Preoperative vs postoperative Lysholm score.

The statistical analysis at the assumed level of significance showed that both in the control and the PRP group there are significant differences with respect to the preoperative examination. Presumably, the changes observed after six weeks are positively correlated with those observed in the following weeks. A single-factor ANOVA analysis was conducted in order to determine in detail the changes in individual parameters over time, the results of which are presented in Table 3.

The statistical analysis at the assumed level of relevance for WOMAC Total results showed a change after the first 6 weeks in both the PRP and control groups. In the case of the PRP group, the improvement continued throughout the entire study period while in the case of the control group, despite the initial decrease, the statistical analysis showed no significant difference between the preoperative and the 24 weeks after the arthroscopy.

In the case of WOMAC stiffness, the statistical analysis showed statistically significant differences with respect to 6 weeks after the administration of PRP, the results were maintained until the end of the period studied. In the case of WOMAC stiffness in the control group, the statistical analysis showed no statistically significant differences in the subsequent tested series.

For the WOMAC function, statistically significant differences were revealed in 6 weeks after the administration of PRP, the results were maintained until the end of the period under examination. In the control group, however, statistically significant differences were observed 12 weeks after the procedure, the result obtained at the end of the examined period did not show statistically significant differences from the preoperative examination.

In the case of WOMAC pain, both in the control and PRP groups, statistically significant differences occurred after only 6 weeks and persisted until the end of the period under investigation.

The Lysholm results showed statistically significant differences between the preoperative examination and the examination performed 24 weeks after the surgery.

The statistical analysis at the assumed level of significance did not show statistically significant differences in individual test sections between the control group and the PRP group. A comparison of mean values with error bars containing standard deviation values in particular groups is presented in Figures 3-7.

\section{Discussion}

Osteoarthritis is one of the most common causes of disability in older population. It is well established that osteoarthritic changes in the joints provoke pain, impair joint function, and decrease life quality among affected individuals [3-5]. Total knee replacement is a gold standard for an end-stage disease of the knee joint; however, there is substantial divergence among the orthopedic society of how to treat early osteoarthritic changes in the knee joint. In this study, we have tried to evaluate a 
potentially beneficial method of minimally invasive treatment of arthroscopic microfracturation of chondral defects in the early stages of osteoarthritis. Based on the assumptions that administration of PRP improves the mechanical and histological properties of the cartilage covering the defect, the study reported in this work set out to investigate the clinical effect of PRP augmentation of arthroscopic microfractures in elderly population. Our results show that arthroscopic microfracturation has a beneficial effect on pain and daily activities, which is represented in the decrease in WOMAC and the increase in Lysholm scores. In the past, it was widely believed that microfractures yield best effects in younger population with isolated cartilage defects [12]. Our study shows that age does not compromise the therapeutic effects in older individuals with osteoarthritic changes over 60 years of age. Moreover, good clinical outcome is shown to be attainable in as short as 6 weeks with PRP administration during MFx. Recent studies have indicated that microfractures were the treatment of choice for early osteoarthritic changes in knee and ankle joints. Their authors confirmed a positive effect of the microfracture technique in reducing pain and improving knee function. Duif et al. [37] included 58 patients out of whom a vast majority had grade IV or III cartilage lesions. They have shown good pain relief and improvement in the function of the knee after one year. Degenerative changes treatment was also studied in the ankle joint, where it was also shown that the microfracture technique gives good outcomes as far as the pain relief and function improvement are considered [38]. The effect of microfractures was investigated in detail in regard to histologic and mechanical properties of the regenerative cartilage. It was shown that mechanical properties of the regenerative cartilage after isolated microfractures are inferior to the regenerative cartilage after augmentation of the procedure with PRP intraarticular administration $[17,28]$. The greatest improvements in the knee function and decline in pain were reported in the first 6 weeks in the PRP group, as opposed to the control group, where the improvement was observed after 12 weeks. Our results are consistent with other authors suggesting that microfractures give a quick improvement of the knee function; however, PRP augmentation may accelerate the therapeutic effect. Most of the authors noted the greatest improvement in the first few weeks, after which the improvement was in plateau stage [37-39] for the follow-up time, which is consistent with our findings for the PRP group. In the past, the microfracture technique was mostly used in younger population in focal cartilage defects. However, with the use of PRP, it might be theoretically applicable in older population. There is a limited number of papers concerning the use of the microfracture technique in older population. In our study we have shown that microfracture with or without PRP is a considerable alternative for patients after 60 years of age. In the study conducted by Duif et al. [37], the mean age was also over 60, and the results were comparable with our findings. In a large study [40], where over 29,000 of MFx procedures were evaluated, the two-year revision surgery rate was calculated as $14.65 \%$. Given fast improvement in function and pain relief and less than $15 \%$ revision rate after MFx, the procedure seems to be promising in early stages of OA even in older populations, as was shown in our study. Moreover, arthroscopy prior to total knee replacement was shown by Piedade et al. [41,42] to have no effect on the survival rate of TKA. Encouraging results of in vitro and animal studies on chondral tissue with the use of PRP $[11,23,28,43]$ have been published in the past. In our study, we found that PRP administration accelerates and prolongs the therapeutic effect. The control and PRP groups showed clinical improvement over the course of six weeks, which lasted to the end of the follow-up in the PRP group. Overall, WOMAC score in the control group at the end of the follow-up did not show a significant difference in regard to the preoperative score, which could suggest that PRP has an effect on prolonging clinical effects of treatment. Other studies concerning PRP usage in augmentation of MFx had a follow-up of 24 months, at the end of which the results in pain reduction and function improvement were comparable $[37,39,44]$. The main limitation of the study was the small size of the study group, which was enforced by study funding. The number of participants in the study group could have an impact on overall statistical results of the study; however, the study group is comparable with papers published in the last few years on this subject [44-46]. Another limitation of the study is a high deviation of baseline WOMAC and Lysholm scores among participants, which is 
nonetheless typical of early OA manifestations in affected patients. Base line deviation could also influence Lysholm scores if the patients changed their activity levels during study.

\section{Conclusions}

Arthroscopic microfracture in the early stages of osteoarthritis improves function and reduces pain in an older group of patients. PRP augmentation of the procedure is safe, and may accelerate and prolong the therapeutic effect. The effects of the procedure are notable even in the first six weeks, after which the improvement lasts in an acceptable manner.

Author Contributions: Conceptualization, P.K.; methodology, P.K.; software, R.K.; validation, R.K.; formal analysis, J.J., R.K., and R.M.; investigation, P.K. and R.K.; resources, P.K.; data curation, R.K.; writing-original draft preparation, P.K.; writing-review and editing, R.K.; visualization, R.K.; supervision, A.J. and R.M.; project administration, P.K.; funding acquisition, J.J. and R.K. All authors have read and agreed to the published version of the manuscript.

Funding: The research was financed in the framework of the project Lublin University of Technology-Regional Excellence Initiative, funded by the Polish Ministry of Science and Higher Education (contract no. 030/RID/2018/19).

Conflicts of Interest: The authors declare no conflict of interest.

\section{References}

1. Glyn-Jones, S.; Palmer, A.; Agricola, R.; Price, A.; Vincent, T.; Weinans, H.; Carr, A. Osteoarthritis. Lancet 2015, 386, 376-387. [CrossRef]

2. Cibere, J.; Sayre, E.C.; Guermazi, A.; Nicolaou, S.; Kopec, J.A.; Esdaile, J.M.; Thorne, A.; Singer, J.; Wong, H. Natural history of cartilage damage and osteoarthritis progression on magnetic resonance imaging in a population-based cohort with knee pain. Osteoarthr. Cartil. 2011, 19, 683-688. [CrossRef] [PubMed]

3. Neogi, T. The epidemiology and impact of pain in osteoarthritis. Osteoarthr. Cartil. 2013, 21, 1145-1153. [CrossRef]

4. Johnson, V.; Hunter, D. The epidemiology of osteoarhtritis. Best Pract. Res. Clin. Rheumatol. 2014, 28, 5-15. [CrossRef] [PubMed]

5. Reyes, C.; Garcia-Gil, M.; Elorza, J.; Mendez-Boo, L.; Hermosilla, E.; Javaid, M.; Cooper, C.; Diez-Perez, A.; Arden, N.; Bolibar, B.; et al. Socio-economic status and the risk of developing hand, hip or knee osteoarthritis: A region-wide ecological study. Osteoarthr. Cartil. 2015, 23, 1323-1329. [CrossRef]

6. Castagnini, F.; Sudanese, A.; Bordini, B.; Tassinari, E.; Stea, S.; Toni, A. Total Knee Replacement in Young Patients: Survival and Causes of Revision in a Registry Population. J. Arthroplast. 2017, 32, 3368-3372. [CrossRef]

7. Roberts, V.I.; Esler, C.N.A.; Harper, W.M. A 15-year follow-up study of 4606 primary total knee replacements. J. Bone Jt. Surg. Br. Vol. 2007, 89-B, 1452-1456. [CrossRef]

8. Steadman, J.R.; Rodkey, W.G.; Briggs, K.K. Microfracture: Its History and Experience of the Developing Surgeon. Cartilage 2010, 1, 78-86. [CrossRef]

9. Feagin, J.A.; Steadman, J.R. The Crucial Principles in Care of the Knee; Wolters Kluwer: Alphen aan den Rijn, The Netherlands; Lippincott Williams \& Wilkins: Philadelphia, PA, USA, 2008; ISBN 978-0-7817-7250-1.

10. Steadman, J.R.; Rodkey, W.G.; Singleton, S.B.; Briggs, K.K. Microfracture technique forfull-thickness chondral defects: Technique and clinical results. Oper. Tech. Orthop. 1997, 7, 300-304. [CrossRef]

11. Caplan, A.I. Bone development and repair. Bioessays 1987, 6, 171-175. [CrossRef]

12. Miniaci, A.; Tytherleigh-Strong, G. Fixation of Unstable Osteochondritis Dissecans Lesions of the Knee Using Arthroscopic Autogenous Osteochondral Grafting (Mosaicplasty). Arthrosc. J. Arthrosc. Relat. Surg. 2007, 23, 845-851. [CrossRef] [PubMed]

13. Frisbie, D.D.; Trotter, G.W.; Powers, B.E.; Rodkey, W.G.; Steadman, J.R.; Howard, R.D.; Park, R.D.; McIlwraith, C.W. Arthroscopic Subchondral Bone Plate Microfracture Technique Augments Healing of Large Chondral Defects in the Radial Carpal Bone and Medial Femoral Condyle of Horses. Vet. Surg. 1999, 28, 242-255. [CrossRef] [PubMed]

14. Furukawa, T.; Eyre, D.R.; Koide, S.; Glimcher, M.J. Biochemical studies on repair cartilage resurfacing experimental defects in the rabbit knee. J. Bone Jt. Surg. Am. 1980, 62, 79-89. [CrossRef] 
15. Shapiro, F.; Koide, S.; Glimcher, M.J. Cell origin and differentiation in the repair of full-thickness defects of articular cartilage. J. Bone Jt. Surg. Am. 1993, 75, 532-553. [CrossRef] [PubMed]

16. Miller, B.S.; Steadman, J.R.; Briggs, K.K.; Rodrigo, J.J.; Rodkey, W.G. Patient satisfaction and outcome after microfracture of the degenerative knee. J. Knee Surg. 2004, 17, 13-17. [CrossRef]

17. Milano, G.; Sanna Passino, E.; Deriu, L.; Careddu, G.; Manunta, L.; Manunta, A.; Saccomanno, M.F.; Fabbriciani, C. The effect of platelet rich plasma combined with microfractures on the treatment of chondral defects: An experimental study in a sheep model. Osteoarthr. Cartil. 2010, 18, 971-980. [CrossRef] [PubMed]

18. Margolis, D.J.; Kantor, J.; Santanna, J.; Strom, B.L.; Berlin, J.A. Effectiveness of platelet releasate for the treatment of diabetic neuropathic foot ulcers. Diabetes Care 2001, 24, 483-488. [CrossRef]

19. Marx, R.E.; Carlson, E.R.; Eichstaedt, R.M.; Schimmele, S.R.; Strauss, J.E.; Georgeff, K.R. Platelet-rich plasma: Growth factor enhancement for bone grafts. Oral Surg. Oral Med. Oral Pathol. Oral Radiol. Endod. 1998, 85, 638-646. [CrossRef]

20. Whitman, D.H.; Berry, R.L.; Green, D.M. Platelet gel: An autologous alternative to fibrin glue with applications in oral and maxillofacial surgery. J. Oral Maxillofac. Surg. 1997, 55, 1294-1299. [CrossRef]

21. Nikolidakis, D.; Jansen, J.A. The biology of platelet-rich plasma and its application in oral surgery: Literature review. Tissue Eng. Part B Rev. 2008, 14, 249-258. [CrossRef]

22. Rendu, F.; Brohard-Bohn, B. The platelet release reaction: Granules' constituents, secretion and functions. Platelets 2001, 12, 261-273. [CrossRef] [PubMed]

23. Krüger, J.P.; Hondke, S.; Endres, M.; Pruss, A.; Siclari, A.; Kaps, C. Human platelet-rich plasma stimulates migration and chondrogenic differentiation of human subchondral progenitor cells. J. Orthop. Res. 2012, 30, 845-852. [CrossRef] [PubMed]

24. Johnstone, B.; Hering, T.M.; Caplan, A.I.; Goldberg, V.M.; Yoo, J.U. In vitro chondrogenesis of bone marrow-derived mesenchymal progenitor cells. Exp. Cell Res. 1998, 238, 265-272. [CrossRef] [PubMed]

25. Blaney Davidson, E.N.; Vitters, E.L.; van der Kraan, P.M.; van den Berg, W.B. Expression of transforming growth factor-beta (TGFbeta) and the TGFbeta signalling molecule SMAD-2P in spontaneous and instability-induced osteoarthritis: Role in cartilage degradation, chondrogenesis and osteophyte formation. Ann. Rheum. Dis. 2006, 65, 1414-1421. [CrossRef]

26. Hickey, D.G.; Frenkel, S.R.; Di Cesare, P.E. Clinical applications of growth factors for articular cartilage repair. Am. J. Orthop. 2003, 32, 70-76.

27. Nixon, A.J.; Fortier, L.A.; Williams, J.; Mohammed, H. Enhanced repair of extensive articular defects by insulin-like growth factor-I-laden fibrin composites. J. Orthop. Res. 1999, 17, 475-487. [CrossRef]

28. Milano, G.; Deriu, L.; Sanna Passino, E.; Masala, G.; Manunta, A.; Postacchini, R.; Saccomanno, M.F.; Fabbriciani, C. Repeated platelet concentrate injections enhance reparative response of microfractures in the treatment of chondral defects of the knee: An experimental study in an animal model. Arthroscopy 2012, 28, 688-701. [CrossRef]

29. Bauer, T.; Boisrenoult, P.; Jenny, J.-Y. Post-arthroscopy septic arthritis: Current data and practical recommendations. Orthop. Traumatol. Surg. Res. 2015, 101, S347-S350. [CrossRef]

30. Barnett, A.J.; Toms, A.D. Revision Total Hip and Knee Replacement. Clin. Geriatr. Med. 2012, 28, 431-446. [CrossRef]

31. Boffa, A.; Previtali, D.; Altamura, S.A.; Zaffagnini, S.; Candrian, C.; Filardo, G. Platelet-Rich Plasma Augmentation to Microfracture Provides a Limited Benefit for the Treatment of Cartilage Lesions: A Meta-analysis. Orthop. J. Sports Med. 2020, 8. [CrossRef]

32. Cameron, M.L.; Briggs, K.K.; Steadman, J.R. Reproducibility and Reliability of the Outerbridge Classification for Grading Chondral Lesions of the Knee Arthroscopically. Am. J. Sports Med. 2003, 31, 83-86. [CrossRef] [PubMed]

33. Dhurat, R.; Sukesh, M. Principles and methods of preparation of platelet-rich plasma: A review and author's perspective. J. Cutan. Aesthet Surg. 2014, 7, 189. [CrossRef] [PubMed]

34. Bellamy, N.; Buchanan, W.W.; Goldsmith, C.H.; Campbell, J.; Stitt, L.W. Validation study of WOMAC: A health status instrument for measuring clinically important patient relevant outcomes to antirheumatic drug therapy in patients with osteoarthritis of the hip or knee. J. Rheumatol. 1988, 15, 1833-1840. [PubMed]

35. Tegner, Y.; Lysholm, J. Rating systems in the evaluation of knee ligament injuries. Clin. Orthop. Relat. Res. 1985, 43-49. [CrossRef] 
36. Rabiej, M. Analizy Statystyczne z Programami Statistica i Excel; Helion: Gliwice, Poland, 2018; ISBN 978-83-283-3922-4.

37. Duif, C.; Vogel, T.; Topcuoglu, F.; Spyrou, G.; von Schulze Pellengahr, C.; Lahner, M. Does intraoperative application of leukocyte-poor platelet-rich plasma during arthroscopy for knee degeneration affect postoperative pain, function and quality of life? A 12-month randomized controlled double-blind trial. Arch. Orthop. Trauma Surg. 2015, 135, 971-977. [CrossRef]

38. Guney, A.; Akar, M.; Karaman, I.; Oner, M.; Guney, B. Clinical outcomes of platelet rich plasma (PRP) as an adjunct to microfracture surgery in osteochondral lesions of the talus. Knee Surg. Sports Traumatol. Arthrosc. 2015, 23, 2384-2389. [CrossRef]

39. Lee, G.W.; Son, J.-H.; Kim, J.-D.; Jung, G.-H. Is platelet-rich plasma able to enhance the results of arthroscopic microfracture in early osteoarthritis and cartilage lesion over 40 years of age? Eur. J. Orthop. Surg. Traumatol. 2013, 23, 581-587. [CrossRef]

40. Frank, R.M.; McCormick, F.; Rosas, S.; Amoo-Achampong, K.; Erickson, B.; Bach, B.R.; Cole, B.J. Reoperation Rates After Cartilage Restoration Procedures in the Knee: Analysis of a Large US Commercial Database. Am. J. Orthop. 2018, 47. [CrossRef]

41. Piedade, S.R.; Pinaroli, A.; Servien, E.; Neyret, P. TKA outcomes after prior bone and soft tissue knee surgery. Knee Surg. Sports Traumatol. Arthrosc. 2013, 21, 2737-2743. [CrossRef]

42. Piedade, S.R.; Pinaroli, A.; Servien, E.; Neyret, P. Is previous knee arthroscopy related to worse results in primary total knee arthroplasty? Knee Surg. Sports Traumatol. Arthrosc. 2009, 17, 328-333. [CrossRef]

43. Hildner, F.; Eder, M.J.; Hofer, K.; Aberl, J.; Redl, H.; van Griensven, M.; Gabriel, C.; Peterbauer-Scherb, A. Human platelet lysate successfully promotes proliferation and subsequent chondrogenic differentiation of adipose-derived stem cells: A comparison with articular chondrocytes: Human platelet lysate promotes proliferation/chondrogenic differentiation of ASCs. J. Tissue Eng. Regen. Med. 2015, 9, 808-818. [CrossRef] [PubMed]

44. Mancò, A.; Goderecci, R.; Rughetti, A.; De Giorgi, S.; Necozione, S.; Bernardi, A.; Calvisi, V. Microfracture versus microfracture and platelet-rich plasma: Arthroscopic treatment of knee chondral lesions. A two-year follow-up study. Joints 2016, 04, 142-147. [CrossRef] [PubMed]

45. Papalia, R.; Diaz Balzani, L.; Torre, G.; Tirindelli, M.C.; Nobile, C.; Maffulli, N.; Denaro, V. Intraoperative application Platelet rich fibrin, postoperative injections OF PRP or microfracture only for osteochondral lesions of the knee: A five-year retrospective evaluation. J. Biol. Regul. Homeost. Agents 2016, 30, 41-49. [PubMed]

46. Manunta, A.F.; Manconi, A. The treatment of chondral lesions of the knee with the microfracture technique and platelet-rich plasma. Joints 2013, 1, 167-170. [CrossRef] [PubMed]

Publisher's Note: MDPI stays neutral with regard to jurisdictional claims in published maps and institutional affiliations.

(C) 2020 by the authors. Licensee MDPI, Basel, Switzerland. This article is an open access article distributed under the terms and conditions of the Creative Commons Attribution (CC BY) license (http://creativecommons.org/licenses/by/4.0/). 